\title{
A History of Electronic Music at the University of Iowa
}

\author{
PAUL DUFFY \\ $\mathrm{PhD}$ candidate in composition, University of Iowa, USA \\ Email: paul-duffy@uiowa.edu
}

\begin{abstract}
This article provides a close study of the University of Iowa Electronic Music Studios. The point of such a detailed account of one studio is to shed light on activity within the field of electronic music that previously did not occupy a place in the literature. Few of the studios listed in Hugh Davies's International Electronic Music Catalog have received detailed attention. Until a wider range of close studies that pay attention to the particularities of individual cases becomes available, it will be difficult to do the comparative work necessary to gain an appropriately textured overall account of the development of electronic music in the post-war period. As these detailed studies, based largely on first-hand documentation, increase the resolution of electronic music's history, they may highlight significant but previously unnoticed, or at least under-appreciated, patterns in the development of electronic music and act as an effective barometer of changing trends.
\end{abstract}

\section{INTRODUCTION}

The University of Iowa Electronic Music Studios were established in 1964. They were one of the first studios in the world with real-time digital synthesis capabilities, and for the past several years, the studios have been among the top five results for Google searches on 'electronic music studios'. Since their founding, the studios have accumulated over 340 alumni and facilitated the composition of over 550 works. Alumni from the studios have recently been awarded the Rome Prize in Composition, a Kennedy Center Award for Meritorious Achievement in Music Composition, a Grammy Nomination for record engineering and an award for Best Conference Paper at the 2013 International Computer Music Conference. A number of alumni have published textbooks, including Charles Dodge's Computer Music: Synthesis, Composition, and Performance, Robert Rowe's Machine Musicianship, and Donald E. Hall's Musical Acoustics, now in its third edition.

The studios' founding was brought about by individuals outside the field of music. James Van Allen, who was appointed head of the Department of Physics and Astronomy in 1951, approached the School of Music in 1963 about the prospect of developing an electronic music studio. His goal was to have James Cessna, a Master of Science candidate in Physics and Astronomy, develop an arbitrary waveform generator that could function as a music synthesiser. The School of Music capitalised on this opportunity and hired Robert Shallenberg in 1964 to direct the new studio. Influence from the sciences was a common theme in the founding of early studios, such as those at Dartmouth and the universities of Illinois and Toronto (Bohn n.d.; Schaeffer 1963: 73; Beecroft 1977: 399; Appleton 2015). Even the Columbia-Princeton Electronic Music Center was founded partly to facilitate shared usage and maintenance of a technologically innovative piece of equipment (Rockefeller Foundation 1958: 282-3; Patterson 2011: 490).

The Iowa Studios have had four directors over the past five decades. Robert Shallenberg (1964-69) oversaw the construction of Cessna's arbitrary waveform generator, the acquisition of a Moog III synthesiser and the graduation of notable alumni such as Cessna, who went on to design the time-of-flight circuitry on NASA's Galileo spacecraft, Cleve Scott, who developed the electronic music studio at Ball State University, and electric string instrument designer Eric Jensen.

Peter Tod Lewis (1969-81) used funds from a Rockefeller Foundation grant to further outfit the studios with sophisticated analog equipment and foster a tradition of composition and performance that often featured live electronics. One of the high points in this tradition was the creation of the album Iowa Ear Music, which combined material from improvisatory sessions and received a five-star rating from DownBeat Magazine. Major collaborations were undertaken during this period with the recording studio and laser technology under the direction of Lowell Cross.

Another legacy of this period was a tradition of public engagement. While Robert Shallenberg regularly interacted with the press (Callan 1965: 5; Allen 1967: 10), Peter Tod Lewis and his students frequently gave public lectures and concerts, often touring around the state of Iowa to broaden the university's impact (Phillips-Farley 1991: 25). Lewis even used his birthdays as occasions to give informal electronic music concerts (Lewis 1972: 1). This legacy is still visible, from an informal concert series called iHearIC, which was founded by students from the studios, to regular concerts and lectures given not only by the studios but a new Performing Digital Arts Cluster with eight faculty positions. 
In 1975, while Lewis was on sabbatical at the Institute of Sonology (then in Utrecht), several visiting faculty members were brought in, including Robert Ashley, Hubert Howe, Pril Smiley and Morton Subotnik. Alumni from this era include Ralph Jackson, BMI president emeritus, Peter Elsea, long-time director of the electronic music studio at UC Santa Cruz, Steven Syverud, founder of the studio at Northwestern University, former University of Georgia and Oberlin professor Lewis Nielson, University of Illinois professor Heinrich Taube, University of WisconsinMilwaukee professor Jon Welstead, NYU professor Robert Rowe, and instrument designer and author of numerous synthesis design books Thomas Henry.

Under Pulitzer Prize-winning composer Kenneth Gaburo (1982-94), the Electronic Music Studios became the Experimental Music Studios. Gaburo introduced the latest computer technology, including a Commodore Amiga in 1985, which facilitated new approaches to speech, text and image manipulation, some of which are detailed in the 1995 issue of Perspectives of New Music dedicated to Gaburo. Students included Edwin Harkins, Professor at UC San Diego, Bill Wolford, American Composers Forum Director of Artist Services and ASCAP Deems Taylor Award winner Philip Blackburn, and Tape-beatles members Ralph Johnson, Paul Neff and John Heck.

Since 1994, the studios have been under the direction of Lawrence Fritts. In 1996, Fritts initiated the Music Instrument Samples Project, a free online collection of note-for-note samples of musical instruments recorded in an anechoic chamber. In 2000, he organised a series of exchange concerts with institutions in France and Italy, and in 2002, Iowa hosted the SEAMUS National Conference.

Recent EMS alumni have taken teaching positions at the universities of Illinois at Urbana-Champaign, Louisville, Nevada-Reno, North Carolina, North Carolina at Charlotte, Western Washington, Wisconsin Platteville, Wisconsin Stevens Point, Cal Poly Pomona, Lawrence University, Marshall University, Northern Illinois University, Oklahoma City University, Winston Salem State University, Black Hawk College, Coe College, Grinnell College, Hunter College and Kirkwood College.

Despite this level of productivity, little has been written on the Iowa Studios. In fact, in Hugh Davies's 1968 International Electronic Music Catalog, an entry for the University of Iowa states "no information received', perhaps having something to do with the directorial transition from Robert Shallenberg to Peter Tod Lewis (Davies 1968: 187). This problem of obscurity exists even for studios that did submit information for Davies's survey. Very few of the studios listed have received detailed attention. Thus, there is a wealth of work and contributions to the field of electronic music that has gone unacknowledged in the literature. In order to uncover these contributions and construct a more faithful history of electronic music, close studies of individual studios must be undertaken. A wider range of these studies will facilitate the comparative work necessary to gain an appropriately textured overall account of electronic music's development in the post-war period.

As these close studies increase the resolution of electronic music's history, they may highlight significant patterns in the development of electronic music, such as the influences from outside music mentioned above or, for example, difficulties with, and strategies for approaching, public engagement. Similar to highlighting significant patterns, close studies will also act as an effective barometer for changing trends, such as the tendency towards more relaxed concert atmospheres.

\section{BACKGROUND: JAMES VAN ALLEN AND SPACE RESEARCH AT IOWA}

The launch of Sputnik 1 on 4 October 1957 sparked a political storm in America. Public outcry demanded that actions be taken to reestablish a competitive edge over the Soviet Union. Funding for a new satellite project was immediately approved by the United States government (Garber 2007) and resulted in the launch of Explorer 1 less than four months later on 31 January 1958.

Three names are traditionally associated with Explorer 1: Wernher von Braun, William Pickering and James Van Allen. Von Braun designed the Jupiter C rocket that launched the satellite. Pickering, then-director of NASA's Jet Propulsion Laboratory, received von Braun's designs and oversaw construction of the rocket. Van Allen developed the satellite's primary payload: a specialised Geiger-Müller tube used for cosmic ray detection (Gurnett 2016a).

Van Allen, who was appointed head of the University of Iowa's Department of Physics and Astronomy in 1951, used the data from Explorer 1 and Explorer 3 to confirm the existence of radiation belts (now known as the Van Allen Belts) around Earth. Between 1951 and 1977, Van Allen and his team of physicists and engineers, sometimes referred to as the Iowa group (Van Allen 2004: 104; Zell 2015), contributed spaceflight instruments to 55 satellites and 111 rockets (Gurnett 2016b: 1). Early satellites communicated data from orbit using analog equipment; voltages from various instruments on board, such as the Geiger tube, temperature sensors, or the battery, would be converted to frequencies and transmitted to the ground, where they would be converted back into voltages and interpreted.

In 1961, Donald Gurnett, another physicist at Iowa, developed the first digital encoder for satellites 
(Gurnett 2016a: 1). This encoder, first integrated into Explorer 12, consisted of 16 binary counters and shift registers. Incoming data from the onboard instruments were converted into 16-bit binary numbers, and these numbers were then converted into sequences of on-and-off frequencies for transmission to the ground.

Digitisation began to revolutionise space technology. Considering how much innovation occurred in the name of space research, new technologies were bound to find their way into other fields. In 1963, Van Allen himself suggested to James Cessna, a new master's student in Physics, that for his thesis, he should utilise digital technology for the construction of a music synthesiser.

Van Allen met with Philip Bezanson, professor of music and head of Iowa's composition program, to discuss the possibility of establishing a studio in which Cessna could build the digital synthesiser and music students could familiarise themselves with the new technology. Thus, the studio at Iowa owes its existence largely to the interests and actions of people outside the field of music.

Other early studios had a similar beginning: Lejaren Hiller worked as a chemist before founding the University of Illinois Experimental Music Studios, and the University of Toronto Electronic Music Studio was largely furnished by Hugh Le Caine, a physicist employed by Canada's National Research Council who also served the studio as a technical advisor and, according to Gustav Ciamaga, had at least an inspirational role in its founding (Bohn n.d.; Schaeffer 1963: 73; Beecroft 1977: 399).

Further, according to Jon Appleton, it was at the suggestion of John Kemeny, mathematician, computer scientist, author of A Philosopher Looks At Science, and then-President of Dartmouth, that he founded the Bregman Studio in 1967 (Appleton 2015):

Kemeny asked me to build what, in those days, was called an electronic music studio, which really consisted of multiple tape recorders, mixers, and out-board gear, all analog. Kemeny was a scientist. He had been an assistant of Einstein and he wrote the BASIC computer language. He had the vision that eventually everybody would use computers, and at that time that was a pretty unusual thing to say. He was encouraging people in all disciplines to work with computers.

Even the Columbia-Princeton Electronic Music Center was founded to allow shared access to, as well as shared maintenance of, a technologically innovative piece of equipment. The first RCA synthesiser, coinvented by Iowa alum Harry F. Olson, brought about Milton Babbitt's involvement with Otto Luening and Vladimir Ussachevsky (Patterson 2011: 490). The 1958 Rockefeller grant that finally established the studio (Rockefeller Foundation 1958: 282-3) came with an explicit recommendation that the new studio acquire the Mark II synthesiser (Patterson 2011: 490).
It is interesting to note this pattern, but it is perhaps more interesting to consider its implications on a deeper level. The goals of these scientists and engineers were not simply to found a studio, but to explore specific technologies, and the exploration of those technologies often had a lasting impact on studios' directions and interests. At Iowa, space researchers had begun experimenting with digital technology and were seeking new applications for it; at Dartmouth, John Kemeny was seeking similar applications for computer technology, and those interests influenced the creation of the Dartmouth Digital Synthesiser as well as the Able Computer (Appleton 2015). Close research at other studios could illuminate similar motivations as well as unique profiles marked by various technological interests.

\section{EARLY YEARS: ROBERT SHALLENBERG, JAMES CESSNA AND THE AWG}

Sometime during the 1963-64 academic year, Bezanson, a Massachusetts native, announced his intention to depart Iowa the following year for UMass Amherst, where he was to become Chair of the Music Department. His successor at Iowa, Richard Hervig, was tasked with hiring a new faculty member to supervise the studio.

Hervig sent letters to numerous early electronic music pioneers, including Babbitt, Ussachevsky, Gunther Schuller and Charles Wuorinen, asking them to recommend someone who could both supervise the new studio and fill the theory vacancy left by Bezanson (Hervig 1964: 1). Hervig wanted someone with a PhD as well as considerable experience in electronic music, although Wuorinen cautioned that 'all of the people ... who would be qualified to advise or administer an electronic studio are quite without the desired Doctorate' (Wuorinen 1964: 1).

Ussachevsky recommended Bülent Arel, who had been working at Columbia-Princeton since 1959 and had assisted Edgar Varèse with the electronic portions of Deserts (Shields 1998, 7). Robert Shallenberg, meanwhile, had also applied for the job. Shallenberg earned his $\mathrm{PhD}$ from the University of Illinois and had been a pupil of Kenneth Gaburo. He had also studied with Milton Babbitt; so, in his letter to Babbitt, Hervig inquired about Shallenberg. Babbitt sent back the following recommendation:

I have the highest personal and professional regard for [Shallenberg]. I fear that his rather quiet and unassuming manner has led to his being underrated as a personality. Actually, he is a very strong-minded and strong-willed musician, whose conscientiousness and sense of responsibility has deeply impressed me. (Babbitt 1964: 1)

Shallenberg, who had been teaching at Illinois Wesleyan University, brought some of his students to the spring 
1964 Midwest Composers Symposium, which, at that time, was a biannual meeting between composition students from the Universities of Illinois, Iowa and Michigan, as well as Northwestern University. Shallenberg and Hervig finally met in person, and soon afterward, Shallenberg was hired.

Iowa's studio was originally housed in a Quonset hut with no air conditioning (Allen 1967: 10). The Physics Department loaned several pieces of equipment, including signal-generating and recording devices, to help get the studio on its feet. Together, Shallenberg and Cessna modified the physics equipment to suit their needs. They built a mixer, a patch panel, peripheral instruments, and speakers from kits; they also purchased two professional model Ampex tape recorders (Lewis 1976: 150).

They also continued working on the digital synthesiser, or, more specifically, the arbitrary waveform generator (AWG) (Figure 1). Across the Mississippi, James Beauchamp had recently completed his Harmonic Tone Generator, which used heterodyning to generate a series of harmonically related sine tones and was, at the time, capable of producing six harmonics (Beauchamp 1964: 1-2). Cessna took a different approach, generating waveforms essentially through

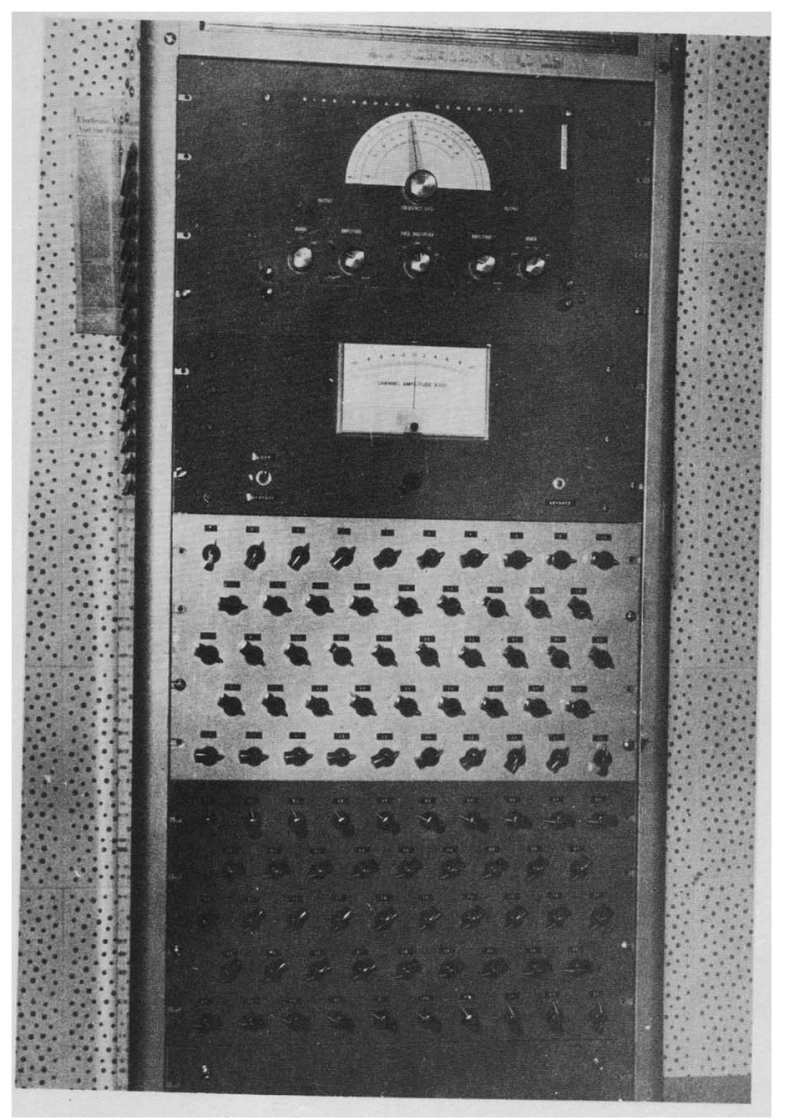

Figure 1. James Cessna's Arbitrary Waveform Generator. The gradual increase and decrease of amplitude on the knobs produces the outline of a sine wave. a reversal of the sampling process. A sequence generator was driven at 96 times a specified waveform period, creating 96 discrete time elements per period. The 96 variable control knobs assigned amplitude values to each time element. These amplitude values were stored in a memory and commutated, producing a set of 'dots' that could be connected and smoothed via filtering (Cessna 1965: 16-17).

Whereas the sum wave's resolution consisted of 96 time elements, the periods of each harmonic were resolved with successively fewer $(96 / n+1$, where $n$ equals the harmonic number) time elements. Thus, the period of the 15th harmonic was resolved with six time elements. This was the AWG's limit for harmonics; Cessna notes that the limiting factor, however, was not so much the time element resolution as the number of low-pass filters available to smooth the harmonic (Cessna 1965: 35-6).

Thus, by the end of the 1964-65 academic year, James Cessna had created a synthesiser capable of generating digitised waveforms. It should be noted that real-time output capability distinguished the AWG from other forms of digital music synthesis at the time, such as MUSIC-N, which utilised the digital computer but required punch cards and, after 'several stages of transformation', resulted in the output of a magnetic tape recording (Tenney 1963: 26).

Along with the AWG, the studio was soon furnished with several other signal generators, including two Hewlett Packard sine wave oscillators, two Heathkit Sine-Square Generators and one Scott Random Noise Source (Shallenberg 1965: 2-3). In those early days, the majority of studio work was devoted to acoustic research rather than composition (Lewis 1976: 150).

James Cessna eventually went on to work for NASA and designed the original time-of-flight circuitry for the Energetic Particles Detector on the Galileo spacecraft, launched in 1989. His role as studio technician was filled by a half-time assistantship. In 1968, the compensation for this position was $\$ 2,700$ per year (Wilson 2016: 8). At first, this assistantship was usually awarded to students in Electrical Engineering or Physics; in recent years, however, it has become more commonly awarded to students from the School of Music.

\section{ROCKEFELLER GRANTS, CNM, PETER TOD LEWIS AND LOWELL CROSS}

In the mid-1960s, the Rockefeller Foundation began awarding grants for the advancement of contemporary chamber music. SUNY Buffalo was the first institution to receive such an award (Rockefeller Foundation 1966: 104). The success of its Center of the Creative and Performing Arts inspired further grants, and in 1966, Iowa received $\$ 100,000$ in matching funds from the Foundation. Thus, the Center for New Music (CNM) was 
created, with Richard Hervig as its head and William Hibbard as its musical director (Phillips-Farley 1991: 22).

The CNM offered students, faculty, and the greater community ample opportunity to experience electronic music. In its first season, which consisted of eight concerts, one concert was dedicated entirely to electronic music; on its programme were Milton Babbitt's Vision and Prayer, Kenneth Gaburo's For Harry and Lemon Drops, Lejaren Hiller's Music Machine, and Karlheinz Stockhausen's Refrain. Other concerts regularly featured electronic pieces by both in-house and outside composers (Phillips-Farley 1991: 6, 25, 31, 37-8, 41, 46-7, 54-5, 63-4).

Community outreach was an important facet of the $\mathrm{CNM}$. There was 'a conscious effort to present to the musical public ... current developments in music' (Phillips-Farley 1991: 94). As part of this conscious effort, studio musicians would give 'presentationdemonstrations' of electronic music equipment at season concerts. The CNM also gave tour concerts across Iowa and brought along electronic equipment to demonstrate its capabilities to a broader audience (Phillips-Farley 1991: 25).

The genre was not always well received, however. In March 1968, a production of King Lear, with electronic incidental music composed by CNM cellist Eric Jensen, was met with a scathing review. D. B. Axelrod, writing for the Daily Iowan, derided the music as 'unpleasing, incongruous, often ridiculous ... sound effects'. Particularly annoying to Axelrod was a 'damnable hum ... it took years to perfect noiseless air conditioning ... Eric Jensen was able to stamp out the progress' (Axelrod 1968: 2). In return, a teaching assistant at the School of Music fired back a letter to the editor alleging that the review 'reveals more about the writer's ignorance than about the subject he purports to discuss ... The whole tenor of his article is so unreasonable that a complete reappraisal of the music seems in order' (Moore 1968: 2).

In order to deepen the arts experience at Iowa and build on the momentum of the CNM, the Center for New Performing Arts (CNPA) was established in 1969 with the aid of a $\$ 25,000$ pilot grant from the Rockefeller Foundation. The CNPA focused on intermedia collaboration, incorporating music, dance, theatre, film, creative writing, and visual plastic arts (Rockefeller Foundation 1970: 130; Phillips-Farley 1991: 21). William Hibbard, director of the CNM, also took on the directorship of the CNPA. The two centers operated independently, although the CNPA's rich interdisciplinary resources had an obvious influence on the CNM's programming. Seven CNM tour concerts between 1970 and 1971, for example, included 'sound sculptures with oscilloscopes, tape pieces, readings, improvisations, films, pieces that encouraged the audience to come onto the stage, and an extract from Shakespeare's Othello' (Phillips-Farley 1991: 29).
Robert Shallenberg left Iowa following the 1968-69 year for a position at Indiana University. He had been 'scouted by theory professor Peter Delone', and he did indeed teach theory courses at Indiana, but he also worked with Iannis Xenakis at the Center for Mathematical and Automated Music (CMAM) and was listed as the CMAM's Assistant Director on its first brochure (Wolcott Turner 2014: 126-7). Before leaving Iowa, Shallenberg greatly enhanced the studio's compositional potential by acquiring a Moog super-module with eight oscillators, six filters, four amplifiers, two envelope generators, a multi-purpose unit, reverb, and delay, among other modules (Lewis 1970a: 1).

In Shallenberg's place, Peter Tod Lewis was hired as Director of the Electronic Music Studios. Lewis was educated on the American coasts, studying at UCSB, UCLA and Brandeis, and lived in Europe for several years before settling down in the midwest (Farley 2007: 1). He was an active participant in the CNM through both composition and performance. Years later, Richard Hervig recalled Lewis's skill with the Moog: 'Peter was terrific ... Peter and the Moog went hand in glove, they really understood each other' (PhillipsFarley 1991: 64).

For Lewis, music-making was an act of celebration. In November of 1972, he celebrated his birthday by giving 'The 40th Annual Peter Lewis Scorpio Celebration-A Concert of Stereo Tape \& Electronic Music Pieces' (Phillips-Farley 1991: 38). A casual affair, the concert's programme was printed with two stipulations at the top: first, the audience was free to move in and out of the hall at their leisure, and second, they need not applaud (Lewis 1972: 1). The programme listed the durations of its pieces, all composed by Lewis, but did so by doubling as a schedule and specifying the time of night at which a given piece would begin and end. Each piece's programme note was prefaced by a quotation, from sources ranging from Peter the Apostle to Franz Kafka.

Lewis continued to hold these Scorpio Celebrations annually. The informal nature of these concerts was probably influenced by a similar trend that had been occurring in American experimental arts since the 1950s, when composers such as John Cage and David Tudor, in collaboration with other artists such as choreographer Merce Cunningham and visual artist Robert Rauschenberg, began experimenting with the presentation of material as much as the material itself (Robinson 2013: 14). Lewis, having been educated on both coasts and having worked with other artists at the MacDowell colony, was probably aware of these alternative performance methods and would have seen in his birthday celebrations the perfect opportunity for an informal concert atmosphere.

After the CNPA's first season, the Rockefeller Foundation followed its pilot grant with a five-year, $\$ 440,000$ matching grant to extend the CNPA's 
funding through 1975. Through the CNPA, Lewis collaborated with filmmaker Franklin Miller; their work produced several award-winning movies, many of which were premiered at CNM concerts. Sondo, for example, premiered at a November 1974 CNM concert and was a winning entry in the Los Angelesbased CURRENTS International Contest for Electronic Music and Film (Phillips-Farley 1991: 43; Schrader 2011: 23).

The CNPA also funded the work of Lowell Cross, who had been collaborating with Carson Jeffries, Professor of Physics at UC Berkeley, on pairing oscilloscopic and laser art with electronic music (Cross 1981: 39; Strange 1983: 235). Before coming to Iowa in the summer of 1971, Cross had built the VIDEO/ LASER and the VIDEO/LASER II, the latter of which was commissioned by Experiments in Art and Technology (EAT) for the 1970 worlds' fair (Expo 70). The VIDEO/LASER II was a mixed-gas (kryptonargon) laser that used a four-colour (red, yellow, blue and green) system (Cross 1981: 39-40). It was installed at the Pepsi-Cola Pavilion, which received over two million visitors throughout the Expo. Inevitably, after EAT turned over the Pavilion's programming, operations and maintenance to Pepsi-Cola, no one was able to properly maintain the VIDEO/LASER II's sophisticated equipment (Cross 2005). This led to its eventual demise and dismantlement at the end of the Expo.

Cross had been recruited by Iowa in 1969 to continue his work with lasers and supervise the recording studio, but the Expo kept him from accepting the position until 1971 (Phillips-Farley 1991: 55). Once in Iowa City, his two primary responsibilities were to establish and operate the recording studios and continue his work with lasers (Phillips-Farley 1991: 55). Thus, he and Jeffries, now working 2,000 miles apart, began developing the VIDEO/LASER III under the auspices of the CNPA.

The system was completed in 1972 and became a regular performance feature both on and off campus. It was unveiled in 1972 at a performance of Cross's own work, Electro-Acoustica, during the opening season of Hancher Auditorium and a new music building. In addition to laser projections and electronic music, Electro-Acoustica featured a symphony orchestra and soloists (Cross 1981: 40). In 1975, the University of Iowa Symphony Orchestra and Kantorei, Iowa's premier choral ensemble, performed Scriabin's Prometheus with visuals provided by the VIDEO/LASER III. Throughout the 1970s, Cross took the system to Davenport, IA, the University of Illinois, Oberlin, Mexico, Germany, Austria and Italy (Cross 1981: 40).

Cross also collaborated with Peter Lewis on several works, pairing synthesisers with the VIDEO/LASER III, and often toured with the CNM (Phillips-Farley 1991: 95). Lewis, meanwhile, had spent his early years at Iowa building the studio's compositional capacity, in terms of both equipment and students. In spring 1970, Lewis sent letters to Tonus inquiring about the purchase of an ARP synthesiser. Although Lewis could not commit to such a purchase at the time, he did mention in a letter to Roger Powell, Applications Engineer at Tonus, how a poster-size portrait of the ARP had been pinned up on a studio wall as a kind of shrine (Lewis 1970b: 1).

The new music building was constructed with two studios, effectively doubling the educational and compositional capacity for electronic music at Iowa. A budgetary increase finally allowed the acquisition of considerable new equipment, including the ARP 2600 as well as an EMS Synthi AKS synthesiser - which Lewis presented at a CNPA concert - a reverb unit, a 16-in quad mixer engineered by Sound 80 with Shure components, a Scully $282-2$ and $282-4$, a Sony $854-4$, and two Ampex tape recorders (Lewis 1970c: 1; Lewis 1971b: 1; Lewis October 1971a: 1; Erickson 1971: 1).

The ARP's portability made it a popular choice for CNM tour concerts. The electronic portion of the concerts usually consisted of a demonstration of live electronics, the performance of a tape piece, and an interactive session in which audience members could approach the stage and 'peer at the machines' (Lewis 1976: 156). Peter Lewis described the demonstrations as 'deadly dull' for himself and probably the audience (Lewis 1976: 60). The following quotation by William Hibbard illustrates the difficulty of bringing new music to the public:

I can't remember all the pieces, but I do remember we did Kenneth Gaburo's Antiphony IV for piccolo, trombone, double bass, and tape. What experience does the small concert-going public in Perry, Iowa, have with new music? How can they possibly be prepared for anything but a lukewarm experience? Even if we had played some totally inoffensive stuff, however beautiful, of George Crumb - even then they would find it very strange to have someone leaning over and putting their fingers into the piano. ... Even if they wanted to go to the local record shop, they wouldn't find a George Crumb. Imagine if they picked up a Babbitt: what could they think? That's the real problem with provincialism; in other words, this type of culture just has no way of getting out into the provinces, except through concerts like this. And I think they are doomed to failure. (Phillips-Farley 1991: 39)

To enliven the demonstrations, Lewis and his colleague, Jon English, a trombonist, began experimenting with live electronics and free improvisation. The two called themselves the 'de Groot Expedition', named after Jan de Groot, a fictitious Iowa pioneer invented by English (Lewis 1976: 156; Lytle, Olive and Parsons 2015). Each improvisation was called a 'variant'. Variant XIII, for example, was performed at a concert on 16 July 1973, by Lewis on the Moog and mixer, English on trombone and mixer, William Parsons on percussion, and Patrick Purswell on flute and piccolo. 
The only pre-conceived structural constraint was that the improv would begin when the lights went down and end when the lights came back up 40 minutes later (Lewis 1976: 157).

Electro-acoustic improvisation became popular at Iowa, both among faculty and students. In the mid-1970s, several students recorded 18 individual improv sessions over five hours. They used the two electronic studios as well as two CNM rooms. All four rooms were routed via XLR to Lowell Cross's recording studio. Thus, musicians in one room could listen on headphones to what musicians in the other rooms were doing and react accordingly. These sessions were edited by Will Parsons and Michael Lytle over a period of two years and, along with other tracks recorded between 1967 and 1976, released on the album Iowa Ear Music. This album received a five-star rating from DownBeat Magazine, and many of its contributors are still in contact with each other. In fall 2015, several of them returned to Iowa City and gave concerts on and off campus (Lytle et al. 2015).

Students during this era included Ralph Jackson, former president of BMI, UC Santa Cruz Professor Peter Elsea, who held the studio technician half-time assistantship between 1974 and 1980, University of Illinois professor Heinrich Taube, Northwestern professor Stephen Syverud, NYU professor Robert Rowe, Oberlin professor Lewis Nielson and University of Wisconsin-Milwaukee professor Jon Welstead.

In fall 1975, Peter Lewis visited the Sonology Institute on sabbatical. During his time away, visiting faculty members and guest composers were brought to campus. Visiting faculty included Robert Ashley, Paul Chihara, Hubert Howe, Edward Miller, Pril Smiley and Morton Subotnick (Phillips-Farley 1991: 46). Fall 1975 CNM concerts were programmed with pieces by these composers, such as Chihara's Logs (1970) and Willow, Willow (1968), Miller's computer-realised accompaniment to Thomas Morley's Christes Crosse (1974) and Subotnick's Until Spring (1975). Guest composers included Luciano Berio, who later gave a presentation on the Iowa studios at IRCAM, Vladimir Ussachevsky and David Tudor.

\section{THE 1980S ONWARD: KENNETH GABURO, LAWRENCE FRITTS AND LOUI}

Peter Lewis continued to run the studios and contribute to the CNM and CNPA until his untimely death from cancer in November 1982, just before his fiftieth birthday. Thus, no Scorpio Celebration was offered that year; instead, the CNM dedicated a memorial concert to Lewis. Four of his pieces were played: Sweets (1965) for piano, played by Professor
Martin Jenni; Bricolage (1979) for tape and percussion, played by CNM percussionist Michael Geary; Signs and Circuits: String Quartet No. 2 (1969), played by the University's Stradivari Quartet; and Gestes III: Douceurs (1980) for tape.

Kenneth Gaburo was hired as the new director. A Pulitzer Prize winner, Gaburo studied at the University of Illinois, where he received his doctorate and remained on faculty. During that time, he taught Robert Shallenberg. After Illinois, Gaburo accepted a position at UC San Diego, where his office consisted of 'bare cement-block walls, a waste basket, one empty file cabinet, two chairs, and one grey metal desk' that was 'filled with crushed cigarette butts'. According to Paul Paccione, 'nobody has thought more about what composing is' (Paccione 1995: 99-100). His works had been regularly programmed on CNM concerts long before his arrival. Before being hired, his works had received $12 \mathrm{CNM}$ performances; this was more than Babbitt, Boulez, Crumb, Dallapiccola, Feldman, Ives, Martino, or Xenakis had received (Phillips-Farley 1991: 91).

Just as Peter Lewis was honoured with a concert of his works, Gaburo was welcomed with an honorary concert of his own. In fall 1983, the CNM performed his Ideas and Transformations No. 1 (1955), Line Studies (1957), andAntiphony IV (Poised) (1966-67) (Phillips-Farley 1991: 65). Gaburo was an active contributor to CNM concerts during his tenure at Iowa; during the 1983-84 season, he directed a concert he titled 'Scratch 1' as an homage to Cornelius Cardew's Scratch Orchestra (Phillips-Farley 1991: 66). This concert included multimedia pieces that used multiple slide projectors and tape recorders.

Like his predecessors, Gaburo was not immune to negative public reaction. One of the pieces performed was his Count-Down (From 20 Sensing ((Instruction)) Compositions). One reviewer offered the following opinion:

I knew I shouldn't have arrived early for the Center for New Music's Saturday evening performance ... the woman to my left, I realized, was not calling out numbers at random, but counting backward at a snail's pace. And (God help us) she was only on 92. (Phillips-Farley 1991: 66)

Gaburo was no stranger to controversy. To him, anything done to subvert habit was valid. Richard Hervig and William Hibbard had also grown accustomed to a certain amount of criticism. Hibbard stated that 'any new piece is a risk ... If I don't hear complaints, then I say we've done something wrong' (Phillips-Farley 1991: 67).

The fact is that the University of Iowa, and perhaps Iowa City in general for that matter, is and has been culturally distinct from the rest of the state. Upon viewing a serene sketch of the Pentacrest - a group of 
five buildings at the center of campus - one writer for The Des Moines Register had the following reaction:

Gee, willickers. This isn't the Pentacrest on the University of Iowa campus that most Iowns know. Where are the protesters, the streakers, the students? (Eckholt 1976: 6B)

Most college towns can relate to this cultural disparity, but rarely is it so pronounced as between the liberal hotbed that is Iowa City and, for example, the ultra-conservative northwestern quadrant of Iowa. Because of this, community outreach and public engagement have been long-standing missions of the university. Through free concerts and presentations on campus and across the state, consistent efforts have been made by UI musicians to offer new music to the general public. The Rockefeller Foundation summarised these goals as such:

These [contemporary chamber ensemble] efforts, while they have been keyed primarily to benefit the composer and performer, have made a major contribution to audience development. The ensembles presented contemporary works in communities which had had little previous contact with the new idioms, and they have developed a loyal and enthusiastic public for this kind of music, particularly in university centers. (The Rockefeller Foundation 1966: 85)

This tradition continues today. The Electronic Studios and the CNM both offer multiple concerts each semester. A Performing Digital Arts Cluster, consisting of eight new faculty hirings across the College of Engineering and the College of Liberal Arts and Sciences, was recently established with the goal of using new technology to foster collaboration across the arts. Numerous smaller programmes exist to extend the arts further out into the public; Arts Share, for example, employs five graduate assistants across the arts and acts as a liaison between the university and clientele who wish to hire UI artists. iHearIC, as another example, is a biweekly concert series hosted at various coffee shops and pubs that regularly features fixed media and live electronics. The importance of bringing music to the public has been demonstrated no more firmly than by the construction of the new Voxman Music Building in the heart of downtown Iowa City.

After battling bone cancer, Kenneth Gaburo passed away in 1993. Lawrence Fritts took over as director of the Electronic Music Studios in 1994 and remains in the position today. One of his primary goals has been to digitise the Studios (Fritts 2016). The Moog super-module and ARP 2600 are still functional and have been experimented with in recent student compositions, but most of the class-directed work is done in Pro Tools and Max 7.

Two semesters of Electronic Media are offered, and their structures are straightforward. The goal of the first semester is to compose a fixed media piece. Students can either record their own sounds using one of 29 studio microphones, or they can use pre-recorded material. The goal of the second semester is to compose a piece for solo instrument and electronics. Source material is gathered in an anechoic chamber on campus and consists of sounds produced by the instrumentalist him or herself, as directed by the composer. These sounds are then used in a Max patch or fixed with Pro Tools. Both semesters culminate in a concert programmed with student works.

The most recently established platform for electronic music at Iowa is LOUi, the Laptop Orchestra of the University of Iowa. LOUi performs both in-house and outside compositions. Past student compositions have used a wide variety of programs, including Max, Pro Tools, Pd, SuperCollider, Melodyne, Ableton and Logic. Performances often include acoustic instruments and incorporate various types of controllers, from touch-sensitive pads to Muse headbands. LOUi's current director is Jean-François Charles, who was hired in spring 2016 as part of the afore-mentioned Performing Digital Arts Cluster.

\section{CLOSING REMARKS}

The Iowa Studios were founded under the unique auspices of a budding space research programme. This led to the creation of original equipment such as the AWG, but it was also part of an international pattern of scientific influence on music. It is hoped that additional close studies of insufficiently documented studios are undertaken, and one possible point of departure could be the circumstances under which those studios were founded. It will be interesting to see if other studios fit into this pattern or stand against it.

Generally, alignment with or deviation from significant patterns will provide interesting points of departure. These patterns may range from well-known issues such as public engagement to unnoticed, or at least under-appreciated, issues. Indeed, the first-hand information close studies provide may very well illuminate trends or connections that were previously unknown. Considering the low percentage of studios in Hugh Davies's survey that have received detailed attention, there is surely a wealth of information about the development of electronic music that is currently unavailable.

Close studies have the potential to not only provide interesting accounts but also elucidate connections between people, studios and events that had been forgotten or unknown. In doing so, authors will fill in the history of electronic music at a detailed level and contribute to a more appropriately textured record than exists now.

\section{REFERENCES}

Allen, R. 1967. Electronic Music is Weird Marriage. The Daily Iowan, 10. 
Appleton, J. 2015. Sowing the Seeds for Today's Electronic Music: An Interview with Jon Appleton. www.kvraudio.com/interviews/sowing-the-seeds-for-todayselectronic-music-an-interview-with-jon-appleton-28724 (accessed 7 May 2017).

Axelrod, D. B. 1968. 'Lear' Music Called Often Ridiculous. The Daily Iowan.

Babbitt, M. 1964. Letter to Richard Hervig. Richard Hervig Papers Box 1. University of Iowa Archives, Iowa City.

Beauchamp, J. 1964. The Harmonic Tone Generator: A Voltage-Controlled Device for Additive Synthesis of Audio Harmonic Spectra. Audio Engineering Society Preprint.

Beecroft, N. 1977. Conversations with Post World War II Pioneers of Electronic Music. Transcribed 2015.

Bohn, J. n.d. Lejaren Hiller. http://ems.music.illinois.edu/ ems/history/hiller (accessed 7 May 2017).

Callan, T. 1965. Composers use Electronics for Music of the Space Age. The Daily Iowan. 5.

Cessna, J. 1965. The Design of a System for the Generation of Arbitrary Periodic Waveforms in the $40 \mathrm{cps}$ to $4 \mathrm{kc}$ Range. MA thesis, University of Iowa.

Cross, L. 1981. The Audio Control of Laser Displays. $d b$, The Sound Engineering Magazine 15(7): 30-41.

Cross, L. 2005. Timeline. www.lowellcross.com/timeline/ laser/ (accessed 7 May 2017).

Davies, H. 1968. International Electronic Music Catalog. Independent Electronic Music Center, Inc.

Eckholt, L. 1976. Iowa Dance 'Feast Continues. The Des Moines Register.

Erickson, G. 1971. Letter to Peter Lewis.

Farley, M. 2007. Liner notes to Peter Tod Lewis. CD, New World Records NWCR619.

Fritts, L. 2016. Personal.

Garber, S. 2007. Sputnik and the Dawn of the Space Age. http://history.nasa.gov/sputnik/ (accessed 7 May 2017).

Gurnett, D. 2016a. Personal interview.

Gurnett, D. 2016b. Spaceflight Instruments Designed and Built at the University of Iowa in the Department of Physics and Astronomy (1951-present). Courtesy of the University of Iowa Dept. of Physics \& Astronomy.

Hervig, R. 1964. Letters to Milton Babbitt, Gunther Schuller, Vladimir Ussachevsky, and Charles Wuorinen. Richard Hervig Papers Box 1. University of Iowa Archives, Iowa City.

Lewis, P. 1970a. Composer's Manual.

Lewis, P. 1970b. Letter to Roger A. Powell, 4 November.

Lewis, P. 1970c. Letter to Alfred Mayer, 5 October.
Lewis, P. 1971a. Letter to Hubert H. Howe, Jr, 10 October. Lewis, P. 1971b. Letter to Don Buchla, 27 September.

Lewis, P. 1972. The 40th Annual Peter Lewis Scorpio Celebration. Concert program.

Lewis, P. 1976. Electronic Music at the University of Iowa. Interface 5(3): 149-70.

Lytle, M., Olive, D. and Parsons, W. 2015. Video Interview with Lawrence Fritts.

Moore, A. 1968. Music Student Refutes ‘King Lear’ Review. The Daily Iowan.

Paccione, P. 1995. Gaburo - Notes on... Perspectives of New Music 33(1/2): 98-112.

Patterson, N. 2011. The Archives of the Columbia-Princeton Electronic Music Center. Music Library Association Notes 483-502.

Phillips-Farley, B. 1991. A History of the Center for New Music at the University of Iowa, 1966-1991. Diss., University of Iowa.

Robinson, S. M. 2013. Chamber Music in Alternative Venues in the 21st-Century U.S.: Investigating the Effect of New Venues on Concert Culture, Programming and the Business of Classical Music. Diss., University of Illinois at Champaign-Urbana.

The Rockefeller Foundation. 1958. Annual Report for 1958.

The Rockefeller Foundation. 1966. Annual Report for 1966.

The Rockefeller Foundation. 1970. Annual Report for 1970.

Schaeffer, M. 1963. The Electronic Music Studio of the University of Toronto. Journal of Music Theory 7(1): 73-81.

Schrader, B. 2011. CURRENTS at the Theatre Vanguard.

Shallenberg, R. 1965. Studio Manual.

Shields, A. 1998. Liner notes to Columbia-Princeton Electronic Music Center 1961-1973. CD, New World Records 80521.

Strange, A. 1983. Electronic Music: Systems, Techniques, and Controls, 2nd edn. Dubuque, IA: W. C. Brown.

Tenney, J. 1963. Sound Generation by Means of a Digital Computer. Journal of Music Theory 7(1): 24-70.

Turner, C. W. 2014. Xenakis in America. Diss., City University of New York.

Van Allen, J. 2004. Origins of Magnetospheric Physics. Iowa City: University of Iowa Press.

Wilson, J. 2016. History of the Electronic Music Studios. Unpublished manuscript, University of Iowa.

Wuorinen, C. 1964. Letter to Richard Hervig.

Zell, H. 2015. A Short History of Earth's Radiation Belts. www.nasa.gov/mission_pages/rbsp/science/rbsp-history. html (accessed 7 May 2017). 